Research Article

\section{Long-term outcome of radiotherapy-induced taste dysfunction in head and neck cancer patients: A pilot study}

\section{Marc Guedea', Andrea Parra ${ }^{2}$, Helena Viñals ${ }^{3}$, Sonia} Almendros ${ }^{4}$, Inés Guix ${ }^{4}$, Isabel Linares ${ }^{4}$, Montse Ventura ${ }^{5}$, Lluis Giner ${ }^{6}$, Ferran Guedea ${ }^{4,7 *}$ and Alicia Lozano ${ }^{8}$

'Odontologist, Trained at Universitat Internacional de Catalunya (UIC), Barcelona, Spain

${ }^{2}$ Odontologist, Trained at the Faculty of Dentistry, Universitat de Barcelona, Barcelona, Spain

${ }^{3}$ Odontologist, Assistant professor at the Faculty of Dentistry, Universitat de Barcelona, Barcelona, Spain

${ }^{4}$ Specialists in Radiation Oncology at Institut Català d'Oncologia (ICO), Members of Radiobiology and Cancer Group of Bellvitge Biomedical Research Institute (IDIBELL). L'Hospitalet de Llobregat, Barcelona, Spain

${ }^{5}$ Statistitian at Radiation Oncology Department at Institut Català d'Oncologia (ICO), Member of Radiobiology and Cancer Group of Bellvitge Biomedical Research Institute (IDIBELL). L'Hospitalet de Llobregat, Barcelona, Spain

${ }^{6}$ Dean of Odontology at Universitat Internacional de Catalunya (UIC), Barcelona, Spain

${ }^{7}$ Chair of Radiation Oncology Department at Institut Català d'Oncologia (ICO), Head of Radiobiology and Cancer Group of Bellvitge Biomedical Research Institute (IDIBELL). L'Hospitalet de Llobregat, Barcelona, Spain

${ }^{8}$ Specialist in Radiation Oncology and Leader of head and neck cancer tumor board at Institut Català d'Oncologia (ICO), L'Hospitalet de Llobregat, Barcelona, Spain
Received: 01 May, 2020

Accepted: 06 May, 2020

Published: 07 May, 2020

*Corresponding author: Ferran Guedea, MD, PhD, Radiation Oncology Department, Institut Català d'Oncologia (ICO), Hospital Duran i Reynals, Gran Via de I'Hospitalet 199-203, E-08908 L'Hospitalet de Llobregat, Barcelona, Spain, Tel: +34 93 2607722; Fax: +34 93 2607725; E-mail: fguedea@iconcologia.net

Keywords: Taste/radiation effects; Head and neck neoplasms/radiotherapy; Radiotherapy dosage; Tongue/radiation effects

https://www.peertechz.com

Check for updates

\title{
Abstract
}

Aims: Taste dysfunction is a frequent complaint in head and neck cancer patients treated with Radiation Therapy (RT), which impairs nutritional support and affects quality of life. A prospective unicenter pilot study was conducted to assess taste dysfunction of the four basic tastes (sweet, salty, bitter, sour) and umami in four patients receiving $\mathrm{RT}$ for head and neck cancer.

Methods: In four male patients (mean age 56 years) diagnosed with squamous cell carcinoma of the larynx $(n=2)$ and hypopharynx ( $=1)$ and undifferentiated carcinoma of the nasopharynx ( $n=1)$, Volumetric Modulated Arc Therapy (VMAT) was administered with a total dose of 69,9 Gy on the tumor (2,12 Gy per fraction) and 54,12 Gy on risk lymph node areas at risk of suclinical disease (1,64 Gy per fraction), five times each week for 7 weeks. Cisplatin chemotherapy was administered for 3 cycles (every 21 days). The filter-paper disc was used to assess thresholds of sweet, salty, bitter, sour tastes, and the whole-mouth taste method for umami. Testing was performed before RT, at 3 weeks (during RT), at 6 weeks (during RT), at 12 months (after RT) and at 14 months (after RT).

Results: The four basic tastes experienced a decrease in their recognition threshold at 3 and 6 weeks as compared with pre-RT values, but at 12 and 14 months values were similar to those before treatment. The perception of the umami taste follows a pattern similar to the four basic tastes and normalized from the year of starting radiotherapy.

Conclusion: In the long-term, pilot study, the four basic tastes and umami declined during the first 6 weeks after the start of RT but improved up to pre-treatment values after a follow-up of 14 months. Restoration of test abilities is clinically relevant for head and neck cancer patients treated with RT. 


\section{Introduction}

Changes in taste perception as hypogeusia (reduced taste) or ageusia (taste loss) are frequently experienced by patients undergoing radiation therapy (RT) for head and neck cancer $[1,2]$. Taste disturbance is bothersome to the patients and has a significant impact on appetite, patterns of food intake, nutritional support, and quality of life [3-5]. In a systematic review of dysgeusia induced by cancer therapies based on 26 studies, a weighted prevalence of dysgeusia was $56.3 \%$ for chemotherapy only, $66.5 \%$ for RT only, and $76 \%$ for combined chemotherapy and RT [6]. Taste changes are explained by damage to oral mucosa, taste buds, and salivary gland dysfunction caused by RT $[7,8]$. Acute taste complications due to RT have been examined in several studies [2-5,9], but the clinical course of taste dysfunction over the following months after completion of treatment has not been well investigated. Therefore, this pilot study was designed to assess the longterm outcome of taste dysfunction in patients with head and neck cancer receiving RT and cisplatin-based chemotherapy.

\section{Methods}

A prospective pilot study was conducted in four patients diagnosed with head and neck tumors who voluntarily accepted to participate in this pilot study and undergo taste testing before RT and after at least 12 months after RT. These patients were individually diagnosed with T3NoMo squamous cell carcinoma of the larynx, T1N3Mo squamous cell carcinoma of the hypopharynx, T3NoMo squamous cell carcinoma of the larynx, and T1N2Mo undifferentiated carcinoma of the nasopharynx and were referred to the Radiation Oncology Department of Institut Català d'Oncologia (ICO), in Barcelona (Spain) for treatment. All patients had a biopsy and were treated with RT (without surgery) with volumetric modulated arc therapy (VMAT) once a day, five times each week for 7 weeks, in 33 sessions, with a total dose of $69.9 \mathrm{~Gy}$ on the tumor (2.12 Gy per fraction) and 54.12 Gy on risk lymph node areas at risk of subclinical disease (1.64 Gy per fraction). The dose for anterior one third of tongue was 31.25 Gy and the dose for the posterior two thirds of the tongue was 46 Gy. 2. Cisplatin-based chemotherapy was administered for 3 cycles (every 21 days) for 2 patients, and concomitant with RT in 2 patients. The study protocol was approved by the Institutional Review Board and written informed consent was obtained from all participants. Taste tests were performed before RT, at 3 weeks, at 6 weeks, at 12 months and at 14 months.

None of the patients had any intercurrent disorder that affected salivary function, and no concurrent medications altering the taste were administered. The four basic taste (sweet, salty, sour, and bitter) recognition thresholds were measured using the filter-paper disc that was placed at the anterior one third of tongue, at $2 \mathrm{~cm}$ from midline following the recommendations of Nagai, et al. [10] and Okuda [11]. The substances and concentrations used were as follows: sweet (sucrose; 8.8, 73, 292, 585, $2336 \mathrm{mM}$ ), salty (sodium chloride; $52,216,862,1724,3448 \mathrm{mM}$ ), sour (tartaric acid; 1,3, 13, 133 267, $5333 \mathrm{mM}$ ), and bitter (quinine hydrochloride; $0.25,0.50$ $2.52,12.59,100.76 \mathrm{mM})$. The concentrations at each taste were serially scored from disc number 1 (highest) to number 5 (lowest). When the highest concentration could not be detected, a score of 0 was given. The taste recognition for umami, which is less clear-cut than the four basic tastes, was measured using the whole-mouth test method [12], with test solutions of monosodium glutamate $(25,50,75$, and $100 \mathrm{mM})$. The patient was asked to rinse the mouth with distilled water and perceived the umami test of the distilled water. Then, $10 \mathrm{~mL}$ of the lowest concentration was circularly dropped into the mouth using a polyethylene pipette. The subject was asked to identify the taste and then spat out the solution. In case of no recognition, a higher concentration was tested. The concentrations at umami taste was serially scored from number 5 (highest) to number 1 (lowest) following the recommendations of Yamashita, et al. [12]. These scores are the contrary of the four basic tastes. The test recognition measurements were performed before RT, at 3 weeks (during RT), at 6 weeks (during RT), at 12 months (after RT) and at 14 months (after RT).

Data are expressed as absolute numbers for individual test recognition thresholds, and as mean and standard deviation (SD). The Wilcoxon signed-rank test was used for pairwise comparisons of mean values of taste recognition thresholds between each time period. Statistical significance was set at $P<0.05$.

\section{Results}

The four basic tastes (sweet, salty, sour, and bitter) showed a decrease in their recognition threshold at 3 and 6 weeks as compared with pre-RT values, but at 12 and 14 months, values were similar to those before RT (Table 1). The perception of the umami taste follows a similar pattern to that of the four basic tastes and normalized at from the year of starting RT. Statistically significant differences in the mean changes of taste acuities throughout the study period were not found (Table 1). Taste changes observed in each individual patient are shown in Figure 1.

\section{Discussion}

The present study shows that test dysfunction related to head and neck irradiation has a favorable long-term outcome because taste disturbances normalized over the subsequent

Table 1: Changes of taste acuities throughout the study period.

\begin{tabular}{|c|c|c|c|c|c|c|}
\hline \multirow{2}{*}{ Study period } & \multicolumn{5}{|c|}{ Tastes, mean (standard deviation, SD) } \\
\cline { 2 - 6 } & Sweet & Salty & Sour & Bitter & Umami \\
\hline Time point & & & & & \\
\hline Before RT & $2.5(0.33)$ & $3.25(0.92)$ & $2.25(0.33)$ & $2.75(0.92)$ & $1.25(0.25)$ \\
\hline Week 3 & $1.5(1.67)$ & $2(0)$ & $1.75(0.25)$ & $2(1.33)$ & $2(2)$ \\
\hline Week 6 & $0.5(1)$ & $1.25(0.9)$ & $1.5(1)$ & $0.75(0.92)$ & $2.75(3.58)$ \\
\hline 12 months & $2.26(2.25)$ & $3.25(2.25)$ & $2.25(2.25)$ & $3.25(2.25)$ & $1(0)$ \\
\hline 14 months & $3(2)$ & $4(0)$ & $3(2)$ & $3.33(0.33)$ & $1(0)$ \\
\hline $\begin{array}{c}\text { Statistical } \\
\text { comparisons }\end{array}$ & & & & & \\
\hline Before RT vs. week 3 & $P=0.179$ & $P=0.108$ & $P=0.179$ & $P=0.273$ & $P=0.273$ \\
\hline Week 3 vs. week 6 & $P=0.108$ & $P=0.179$ & $P=0.317$ & $P=0.067$ & $P=0.108$ \\
\hline 12 months vs. week 6 & $P=0.108$ & $P=0.108$ & $P=0.465$ & $P=0.108$ & $P=0.144$ \\
\hline 14 months vs. 12 & $P=0.108$ & $P=0.654$ & $P=0.144$ & $P=0.789$ & Not \\
\hline months & & & & & applicable \\
\hline
\end{tabular}

Citation: Guedea M, Parra A, Viñals H, Almendros S, Guedea F, et al. (2020) Long-term outcome of radiotherapy-induced taste dysfunction in head and neck cancer patients: A pilot study. J Dent Probl Solut 7(1): 030-033. DOI: https://dx.doi.org/10.17352/2394-8418.000082 
Sweet taste

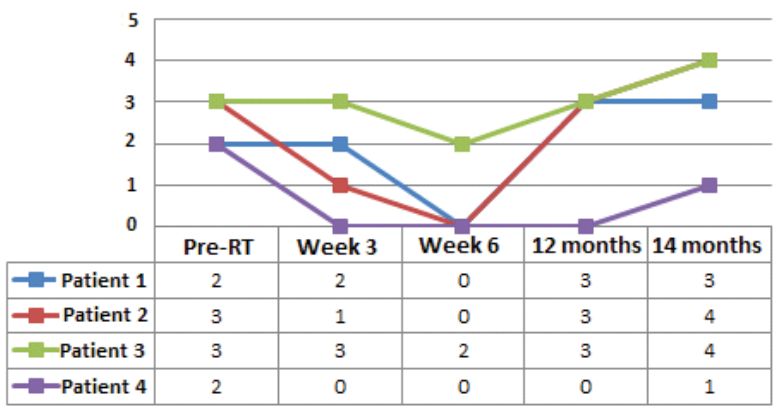

Sour taste

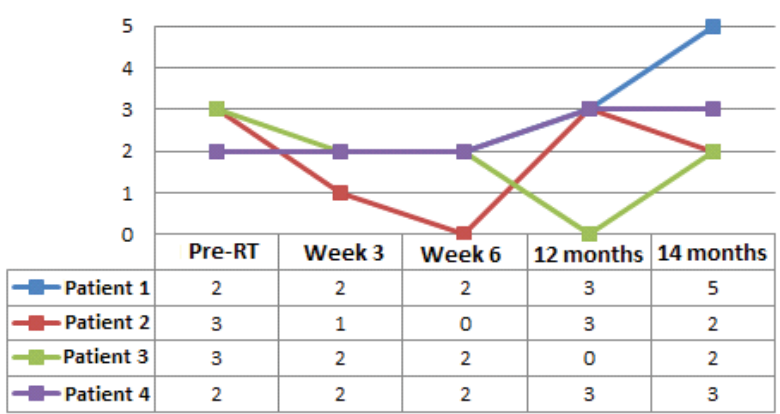

Salty taste

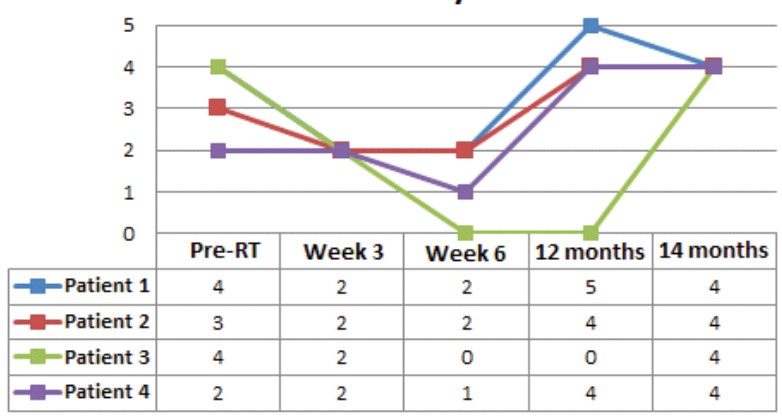

Bitter taste

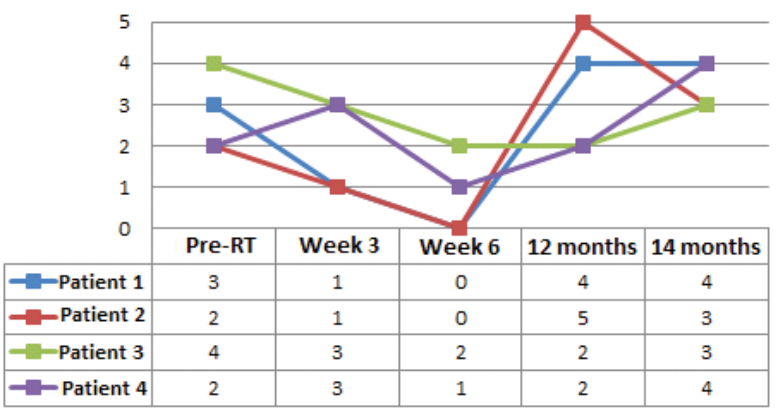

Umami taste

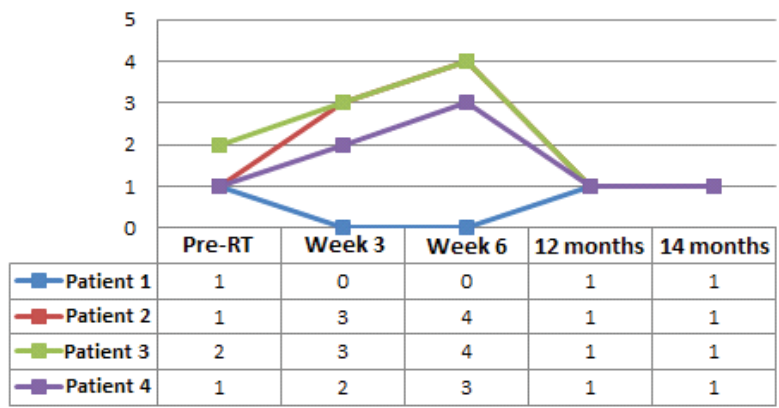

Figure 1: Individual taste changes before radiotherapy and at the last follow-up at 14 months.

months after completion of RT. After a follow-up of 14 months, all four patients had recovered taste acuities at preRT levels. The present results, however, should be interpreted taking into account that this was a pilot study limited to four head and neck cancer patients. With the implementation of new radiation techniques, such as VMAT in head and neck irradiation, toxicity of the radiation dose to the oral tongue and salivary gland tissue can be reduced. Statistically significant differences in changes of taste thresholds during the study period were not observed, which may probably be explained by the small sample size.

\section{Conclusion}

Despite the pilot nature of the study, our encouraging results of long-term resolution of dysgeusia are clinically relevant for patients with head and neck cancer undergoing RT as part of the primary treatment strategy of their malignancy.

\section{Acknowledgements}

We thank CERCA Programme / Generalitat de Catalunya for institutional suport.

We thank Marta Pulido (M.D, Ph.D) for the preparation and review of the manuscript.

\section{References}

1. Mossman K, Shatzman A, Chencharick J (1982) Long-term effects of radiotherapy on taste and salivary function in man. Int J Radiat Oncol Biol Phys 8: 991-997. Link: https://bit.ly/2SILkaV

2. Ruo Redda MG, Allis $S$ (2006) Radiotherapy-induced taste impairment. Cancer Treat Rev 32: 541-547. Link: https://bit.ly/3dlhVLJ

3. Jin S, Lu Q, Jin S, Zhang L, Cui H, et al. (2018) Relationship between subjective taste alteration and weight loss in head and neck cancer patients treated with radiotherapy: A longitudinal study. Eur J Oncol Nurs 37: 43-50. Link: https://bit.ly/3fruguK 
4. Baharvand M, ShoalehSaadi N, Barakian R, Moghaddam EJ (2013) Taste alteration and impact on quality of life after head and neck radiotherapy. J Oral Pathol Med 42: 106-112. Link: https://bit.ly/2SLoRtL

5. Yamashita H, Nakagawa K, Tago M, Nakamura N, Shiraishi K, et al. (2006) Taste dysfunction in patients receiving radiotherapy. Head Neck 28: 508-516. Link: https://bit.ly/3ccT5xq

6. Hovan AJ, Williams PM, Stevenson-Moore P, Wahlin YB, Ohrn KE, et al. (2010) A systematic review of dysgeusia induced by cancer therapies. Support Care Cancer 18: 1081-1087. Link: https://bit.ly/3ds3sh9

7. Baharvand M, ShoalehSaadi N, Barakian R, Moghaddam EJ (2013) Taste alteration and impact on quality of life after head and neck radiotherapy. $\mathrm{J}$ Oral Pathol Med 42: 106-112. Link: https://bit.ly/2SJRjfn

8. Deshpande TS, Blanchard P, Wang L, Foote RL, Zhang X, et al. (2018) Radiationrelated alterations of taste function in patients with head and neck cancer. a systematic review. Curr Treat Options Oncol 19: 72. Link: https://bit.ly/3cf7ljC
9. Irune E, Dwivedi RC, Nutting CM, Harrington KJ (2014) Treatment-related dysgeusia in head and neck cancer patients. Cancer Treat Rev 40: 1106-1117. Link: https://bit.ly/2L4ChN6

10. Nagai A, Kubota M, Katayama Y, Kojima C (2012) Evaluation of taste acuity by the filter-paper disc in Japanese young women: the relationship with micronutrients status. Asia Pac J Clin Nutr 21: 406-410. Link: https://bit.ly/2zknriJ

11. Okuda $Y$ (1980) The method of gustatory test by filter-disc. Nihon Jibiinkoka Gakkai Kaiho 83: 1071-1082. Link: https://bit.ly/3bantHr

12. Yamashita H, Nakagawa K, Hosoi $Y$, Kurokawa A, Fukuda $Y$, et al. (2009) Umami taste dysfunction in patients receiving radiotherapy for head and neck cancer. Oral Oncol 45: e19-e23. Link: https://bit.ly/2Wz96XR

\section{Discover a bigger Impact and Visibility of your article publication with} Peertechz Publications

\section{Highlights}

* Signatory publisher of ORCID

* Signatory Publisher of DORA (San Francisco Declaration on Research Assessment)

* Articles archived in worlds' renowned service providers such as Portico, CNKI, AGRIS, TDNet, Base (Bielefeld University Library), CrossRef, Scilit, J-Gate etc.

* Journals indexed in ICMJE, SHERPA/ROMEO, Google Scholar etc.

* OAI-PMH (Open Archives Initiative Protocol for Metadata Harvesting)

* Dedicated Editorial Board for every journa

* Accurate and rapid peer-review process

* Increased citations of published articles through promotions

* Reduced timeline for article publication

Submit your articles and experience a new surge in publication services (https://www.peertechz.com/submission).

Peertechz journals wishes everlasting success in your every endeavours.

Copyright: ( 2020 Guedea M, et al. This is an open-access article distributed under the terms of the Creative Commons Attribution License, which permits unrestricted use, distribution, and reproduction in any medium, provided the original author and source are credited. 